\title{
Archetypal Energies as the "Creative Urges" behind the evolution of humanistic psychology and positive psychology.
}

\author{
Carroy (Cuf) Ferguson \\ University of Massachusetts-Boston, Boston, MA, USA.
}

This presentation is a brief overview of what can be called authentic Archetypal Energies as the "Creative Urges" behind the evolution of humanistic psychology and positive psychology. The framework is derived from my newest book, evolving the Human Race Game, a book designed to assist readers in evolving human consciousness as we play what I call seven kinds of human race games. In September 2016, the book received the 2016 Living Now Evergreen Bronze Medal Award for Spiritual Leadership. In the book, 25 Archetypal Energies are discussed. They are defined as Higher Vibrational Energies that operate deep within our psyches, at both individual and collective levels. We tend to experience them as "creative urges" to move us toward our optimal selves and optimal realities [1].

In all cultures, based on exhaustive study, each Archetypal Energy has its own transcendent value, purpose, and quality, and "voice" unique to the individual. Easily recognized terms are used to evoke a common sense of these Archetypal Energies (e.g. Trust, Love, Acceptance, Harmony, Inclusion, Patience, Wisdom, Courage, Truth). Below I will briefly reference three types of Archetypal Energies and their functions with respect to how they have and will continue to influence the evolution of humanistic psychology and positive psychology. Anecdotal examples are used to illustrate how the "creative urges" move us toward co-creating optimal conditions for individual and collective growth and how humanistic psychology and positive psychology can play important roles in that regard.

There are four important perspectives related to Archetypal Energies. They are as follows: (1) Everything we experience through our senses is made up of energy; we live in an Energy Vibrational World $\left(\mathrm{E}=\mathrm{MC}^{2}\right.$ or $\left.\mathrm{MC}^{2}=\mathrm{E}\right)$; (2) We are four-fold Consciousness-Energy Beings, with mind-body-emotion-spirit connections; (3) The mind is the carrier of beliefs (thoughts reinforced by emotion and imagination); beliefs structure reality at both individual and collective levels; beliefs are not truths per se; and (4) Thoughts and emotions have electromagnetic properties.

These perspectives flow from what I, and others, call a paradigm shift for how we can energetically relate to the material world. In the old paradigm (a mechanistic view of the self and the vibrational material world), three basic assumptions are at play: (1) Each person and their consciousness are perceived as independent and apart from the material world; (2) The human mind can know this material world "objectively"; and (3) If one can know something, one can therefore control it. However, the new paradigm: (1) Places each person and their consciousness in a vibrationally active and relatively open energy exchange with the material world; (2) Assumes that there is a vibrational relationship between each person as a Consciousness-Energy Being and the material world which is interdependent; individually and collectively, each person and their consciousness, therefore, give rise to the creation of material form, and physical form in turn impacts consciousness; and (3) Assumes that underlying the nature of this interdependence are creative energy principles governing the exchange, transmutation, and transformation of energy.

In this context, what then is Consciousness? Authors like Woodhouse [2], Williamson [3], and Tolle [4,5] imply the following: (1) Consciousness is a transcendental field presupposed by its objects, not simply an object or series of states within that field; (2) Consciousness is not just a mirror of consensus reality, but is the source of manifestation of a spectrum of realities; (3) Consciousness and energy are interconnected aspects of a Great Chain of Being; they share each other's properties, but are not reducible to one another; and (4) Consciousness is the subjective aspect of energy (the inside of energy) and energy, whether in physical forms or in forms not currently recognized by physics, is the outward, objective aspects of consciousness (the outside of consciousness).

The lenses through which we experience our Consciousness-Energy Beingness and a sense of Self and express our Archetypal Energies (creative urges), include race, gender, class, religious or spiritual orientation, culture, ethnicity, tribes or other self-described group affiliations, and nationality. 
The perspectives related to Archetypal Energies and viewing human beings as Consciousness-Energy Beings living in an Energy Vibrational World help us to better understand how we come to experience "creative urges" that can lead us toward our optimal selves and optimal realities. In this regard, I have identified three types of Archetypal Energies (creative urges) and their functions: (1) Foundational Archetypal Energies (Trust; Enthusiasm; Humor; Beauty; Hope; Flexibility; and Courage); (2) Transformational Archetypal Energies (Love; Acceptance; Inclusion; and Harmony); and (3) Spiritually Integrative Archetypal Energies (Understanding; Truth; Wisdom; Patience; Inspiration; Abundance; Compassion; Peace; Joy; Clarity; Vision; Oneness; Unity; Serenity). Quantum researchers, physicists, aura imaging researchers, resonance energy researchers, as well as my own research, suggest that the vibrational frequency of these Higher Vibrations resonate at the highest levels of $\mathrm{Hz}$ and that Love is the highest resonance of $\mathrm{Hz}[6-8]$.

Foundational Archetypal Energies and foundational lessons help each person form or establish a personality structure, a foundation, which has qualities that allow the person to entertain the possibility of choosing to grow, to expand, to move higher, and to do so by choosing a path of growth with Joy.

Transformational Archetypal Energies and transformational lessons focus on the "heart" of each person. The lessons at this level pertain to the changes in the foci and preferences of a person's consciousness and the nature of various blending, transformations, transcendences and transmutations of a person's energies as the person makes authentic contact with deeper parts of themselves and as people make authentic contact with one another.

Spiritually Integrative Archetypal Energies and spiritually integrative lessons help each person to mirror the integration of all aspects of themselves and become what might be called their authentic Truer Self (or what I call Ever Emerging Self). To be one's authentic Truer Self is to "be" and "act out" all or most of one's deeper Archetypal Energies.

In Evolving the Human Race Game, I discuss seven common types of human race games we play as human beings and the "creative urges" (Archetypal Energies) associated with them. The seven types of human race games and their associated "creative urges" are: (1) the Security Human Race Game (Trust); (2) the Sensory Human Race Game (Enthusiasm, Humor, Beauty, Hope); (3) the Power Human Race Game (Flexibility, Courage); (4) the Transformational Human Race Game (Love, Acceptance, Inclusion, Harmony); (5) the Inspirational Human Race Game (Understanding, Truth, Wisdom, Patience, Inspiration); (6) the Altruistic Human Race Game (Abundance, Compassion, Peace, Joy, Clarity, Vision); and (7) the Soul-Source Human Race Game (Oneness, Unity,

\section{Serenity).}

When we allow these Archetypal Energies to freely flow and to be authentically expressed while playing these human race games, we can indeed move toward the co-creation of our optimal selves and optimal realities at individual and collective levels. For example, when a person authentically says, "I love you," what they really mean is "when I'm in your presence, I' $m$ in touch with the deeper Love inside of me." The same can be said for each of the Archetypal Energies.

So, how does all of the above relate to the evolution of humanistic psychology and positive psychology? I would argue that the primary Archetypal Energies fueling the founding and evolution of humanistic psychology were "creative urges" associated with the Inspirational Human Race Game (Inspiration, Understanding, Wisdom) and the Altruistic Human Race Game (Vision), all Spiritually Integrative Archetypal Energies with electromagnetic properties. For example, from a consciousness-energy point of view, the vibrational fuel and "creative urge" of Inspiration for humanistic psychology flow from: (1) phenomenological and existentialist "thought" [9]; (2) the "philosophical thoughts" of Eastern philosophy and Judeo-Christian philosophies of influential figures of personalism [10-12]; (3) psychologists in the early 1930s and again in the late 1950s that became interested in uniquely human issues (i.e., self, self-actualization, health, hope, love, creativity, nature, being, becoming, individuality, meaning); and (4) the works of Carl Rogers [13] and Abraham Maslow [14].

From a consciousness-energy point of view, the vibrational fuel and "creative urge" of Vision manifested itself in 1962 as the founders of humanistic psychology and the Association for Humanistic Psychology presented a bold, new Evolutionary Vision for Human Potential, giving birth to, stimulating, and nurturing a profound shift in Consciousness for how we can "think anew" about ourselves as human beings. No longer were we to focus on what's wrong with us as human beings or how we are or have been conditioned. Rather, the door was opened to focus on how we can "become" and "be" our Optimal Selves. The bold Vision culminated in the First Invitational Conference on Humanistic Psychology the weekend of November 28-30, 1964 (Old Saybrook I Conference), which was re-visioned on May 11-14, 2000 at the State University of West Georgia (Old Saybrook II Conference).

From a consciousness-energy point of view, the vibrational fuel and "creative urge" of Understanding is revealed in five basic principles of humanistic psychology, as articulated by Bugenthal in The Search for Authenticity and adapted by Tom Greening when he was Editor of the Journal of Humanistic Psychology [15]. A principle is a kind of rule, belief, or idea that guides you. The five basic principles are: (1) Human beings cannot be reduced to components (i.e., they supersede the sum of their parts); 
(2) Human beings have their existence in a uniquely human context, as well in a cosmic ecology; (3) Human consciousness includes an awareness of oneself in the context of other people (i.e., they are aware and are aware of being aware; they are conscious); (4) Human beings have choices and responsibilities (i.e., they have the ability to make choices and therefore have responsibility); and (5) Human beings are intentional; they seek meaning, value and creativity (i.e., they aim at goals and are aware that they cause future events).

From a consciousness-energy point of view, the vibrational fuel and "creative urge" of Wisdom can be seen in how humanistic psychology proposes we examine the human experience, be helpful, and grow. Humanistic psychology suggests we focus on: (1) a holistic approach to scientific research that advocates methodological pluralism, qualitative methods to research "lived experiences" and quantitative methods that do not level the phenomena (e.g. the length of time spent crying or laughing); (2) empathy as one of the most important aspects of humanistic therapy; and (3) self-esteem as important for self-actualization.

In terms of positive psychology, I would argue that the primary Archetypal Energies fueling the emergence and evolution of positive psychology were similar "creative urges" associated with the Inspirational Human Race Game (Inspiration, Understanding), but that there were different "creative urges" associated with the Altruistic Human Race Game (Joy, Peace), again all Spiritually Integrative Archetypal Energies, with electromagnetic properties. In this light, positive psychology is an outgrowth of and emerged from humanistic psychology.

More specifically, from a consciousness-energy point of view, the vibrational fuel and "creative urge" of Inspiration for positive psychology emerged from the following sources: (1) In Motivation and Personality, Maslow first used the term positive psychology [16]; (2) Other psychologists like Carl Rogers and Erich Fromm developed theories and practices pertaining to human happiness and flourishing, both tenets of positive psychology [13]; and (3) Martin Seligman in 1998 popularized the notion of positive psychology by choosing it as a theme for his term as president of the American Psychological Association.

From a consciousness-energy point of view, the vibrational fuel and "creative urge" of Understanding that influence positive psychology may be characterized by the following "thought patterns": (1) Positive psychology is the latest effort by human beings to understand the nature of happiness and well-being; (2) Some methods for understanding attempt to identify the amount of positive affect from one activity to the next; (3) The promising methods of neuroscience (e.g. neural correlates for emotions) and brain scanning to understand happiness and sadness are utilized; and (4) Evolutionary biologists are seeking to understand what features in the brain allow humans to distinguish between positive and negative states of mind, and what features improve humans' ability to strive and reproduce.

From a consciousness-energy point of view, the vibrational fuel and "creative urge" of Joy is exemplified by the foci of positive psychology and by the foci of various studies in this field. Some examples are as follows: (1) In terms of foci, positive psychology is concerned with four issues: positive thoughts, positive emotions, positive individual traits, and positive institutions; and (2) Many studies have sought to demystify the factors in happiness; studies, for example, have looked into issues like age, gender, personal finances, education and intelligence, parenthood, marriage, personality, social ties, weather, religion, spirituality, culture, political views, addiction, suffering, changes in happiness levels and happiness set point.

In consciousness-energy terms, emotions tend to follow the flow of one's reasoning, whereby positive thinking electromagnetically attracts related benefits. More specifically, in terms of positive thinking, researchers are finding more and more evidence regarding the benefits of optimism and positive thinking. Findings suggest that: (1) Positive thinkers tend to cope better with stress (e.g. researchers have found that when optimists encounter a disappointment, they are more likely to focus on things they can do); (2) Optimism has been shown to improve one's immunity (e.g. researchers have found that activation in brain areas associated with negative emotions lead to a weaker immune response to a flu vaccine, while optimistic people exhibited a stronger immune response than those with a negative view of a particular situation); (3) Positive thinking has been found to be good for one's health (e.g. The Mayo Clinic reports a number of health benefits associated with optimism, including a reduced risk of death from cardiovascular problems, less depression, and an increased lifespan) [17]; (4) Positive thinking has been found to contribute to people being resilient (e.g. researchers have found that in the wake of a crisis, such as a terrorist attack or natural disaster, positive thoughts and emotions encourage thriving and provide a sort of buffer against depression among resilient people); and (5) "Instead of ignoring reality in favor of the silver lining, psychologists suggest that positive thinking centers on a belief in your abilities, a positive approach to challenges, and trying to make the most of bad situations" [18]. Such benefits can create the conditions for experiencing a greater sense of Joy and (Inner) Peace.

From a consciousness-energy point of view, the vibrational fuel and "creative urge" for having and experiencing (Inner) Peace is reflected by positive psychology researchers' more recent focus on what is called PERMA, and by the emergence of new supportive technologies. "P" stands for Positive Emotions, a wide range of feelings like happiness, joy, excitement, 
satisfaction, pride and awe. "E" stands for Engagement, the involvement in activities that draw upon one's interests and lead to flow or a sense of ecstasy and clarity. "R" stands for Relationships that fuel positive emotions. "M" stands for Meaning and Purpose, which prompts the question of "Why?" and puts everything into context from work to relationships to other parts of life. "A" stands for Accomplishments, the pursuit of success and mastery. Each PERMA element contributes to well being, is pursued for its own sake, and is defined and measured independently of other elements. Additionally, supportive technologies like those developed by HearthMath also reflect an emphasis on positive emotions and well being (e.g. emWave2 provides heart rhythm feedback and training in real time to help a person shift to a positive emotional state in a moment) [19].

The evolution of both humanistic psychology and positive psychology have been fueled, therefore, by Archetypal Energies ("creative urges") in their own unique ways to play the Inspirational Human Race Game and the Altruistic Human Race Game. Moving forward, these psychologies can partner and play more gracefully by promoting the Archetypal Energy Joy, associated with the Altruistic Human Race Game, and by embracing some Archetypal Energies ("creative urges") associated with the Transformational Human Race Game (Love, Acceptance, Inclusion, and Harmony) and the Soul-Source Human Race Game (Oneness and Serenity). In my view, humanity could benefit greatly by such a joint effort.

My sense is that the next evolutionary step for humanity is to learn how to grow with Joy. We already know how to grow with pain. In this regard, there is an old African proverb that could prove useful as a guide: "I am because we are. We are because I am."

\section{References}

1. Ferguson C. Evolving the human race game: A spiritual and soul-centered perspective. Tate Publishing \& Enterprises, Mustang, OK 2014.
2. Woodhouse M. Paradigms wars: Worldviews for a new age. North Atlantic Books, Berkeley 1996.

3. Marianne W. The gift of change: Spiritual guidance for living your best life. Harper Collins Publishers, New York 2006.

4. Tolle E. The power of now: A guide to spiritual enlightenment. New World Library, Novato 2004.

5. Tolle E. A new earth: Awakening to your life's purpose. Penguin Group Inc., New York 2008.

6. Wolf FA. Touchstone. Parallel Universes, New York 1990.

7. Bohm D. Wholeness and the implicate order. Routledge classics, New York 2002.

8. Korotkov K. Light after life: A scientific journey into the spiritual world. Fair Lawn, Backbone Publishing Company 1998.

9. Wilkerson D, Nietzsche F. The internet encyclopedia of philosophy 2015.

10. Mournier E. Existentialist philosophies an introduction. Rockliff Publishing Corporation, London, England 1947.

11. Marcel G. The mystery of being, reflection and mystery. St. Augustine Press Inc., South Bend, IN 2001; 1.

12. De Rougemont D. The future is within us. Pergamon Press, MO 1983.

13. Rogers C. Client-centered therapy. Houghton Mifflin, Chicago, IL 1965

14. Maslow A. Toward a psychology of being. Van Nostrand Reinhold Company, New York 1962.

15. Bugenthal J. The search for authenticity: An existentialanalytic approach to psychotherapy. Holt, Rinehart and Winston, Austin, TX 1965.

16. Maslow A. Motivation and personality. Harper \& Brothers, New York 1954.

17. Mayo Clinic. Positive thinking: Reduce stress by eliminating negative self-talk 2011.

18. Cherry K. Benefits of positive thinking 2016.

19. http://www.heartmath.com/

\section{Correspondence to:}

Dr. Carroy U (Cuf) Ferguson, PhD

University of Massachusetts-Boston, 100 Morrissey Blvd.,

Boston, MA 02125,

USA.

Tel: 857-205-1152

E-mail: Carroy.Ferguson@umb.edu 